УДК 550.34

\title{
ТРЕЩИННОЕ ТОЛБАЧИНСКОЕ ИЗВЕРЖЕНИЕ В 2012-2013 ГГ. ПЕРВЫЕ РЕЗУЛЬТАТЫ
}

\author{
(С) 2013 г. Академик Е. И. Гордеев, Я. Д. Муравьев, С. Б. Самойленко,
} А. О. Волынец, Д. В. Мельников, В. Н. Двигало

Поступило 24.04.2013 г.

\author{
DOI: $10.7868 / \mathrm{S} 0869565213300208$
}

27 ноября 2012 г. в 17:15 местного времени (5:15 UTC) южнее вулкана Плоский Толбачик из образовавшегося разлома субмеридионального простирания началось излияние лавы. Длина разломной зоны составила около 6 км в диапазоне высот от 2200 до 1500 м. 28 ноября отмечен пеплопад в север-северо-восточном направлении на удалении до 100 км, а также фонтанирование лавы из двух эруптивных центров. Сильный грохот и гул отмечались в населенных пунктах на расстоянии в 40-50 Км, 29-30 ноября - умеренная эксплозивная деятельность, излияние лавы на верхнем эруптивном центре, интенсивное фонтанирование лавы и активное продвижение лавовых потоков в нижней части разлома. Первого декабря деятельность верхнего прорыва прекратилась. Длина лавового потока верхнего прорыва составила 9 км, площадь 5.6 км²$^{2}$. С начала декабря извержение сосредоточилось в нижней части прорыва с излиянием жидкой лавы гавайского типа из трещины длиной около 1 км на высотах 1500-1600 м.

Лавовые потоки относятся к гавайскому типу “пахоэ-хоэ” мощностью 1-2 м у истока и 3-5 м во фронтальной части. Лавы образуют различные формы типа канатных лав и лавовых подушек. Создают систему лавоводов. Максимальная измеренная температура расплава составляет около $1100^{\circ} \mathrm{C}$. Плотность лавы рассчитывали по химическому составу и измеряли непосредственно. Для лав прорыва, излившихся в первый день извержений, расчетная плотность составляет от 2.65 до 2.58 г $/ \mathrm{cm}^{3}$ при температуре $1100^{\circ} \mathrm{C}$ и весовом содержании воды от 0 до $1 \%$. При этих же условиях расчетная плотность лав нижней части прорыва находится в диапазоне от 2.7 до

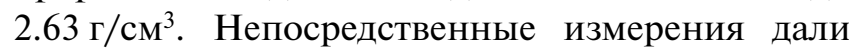

Институт вулканологии и сейсмологии Дальневосточного отделения

Российской Академии наук, Петропавловск-Камчатский

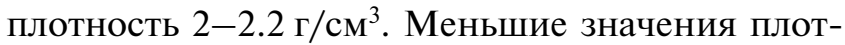
ности по измерениям вызваны присутствием законсервированной газовой компоненты. Эффективная вязкость составляла в начале извержения $10^{4}$ Па · с и в январе 2013 г. $(1.5-3) \cdot 10^{2}$ Па · c.

Извержение произошло в Толбачинской региональной зоне шлаковых конусов, площадь которой составляет около $900 \mathrm{kM}^{2}$ и протяженность 70 км. В южной части зона имеет север-северо-восточное направление, далее пересекает вулкан Плоский Толбачик, изменяя простирание на северовосточное. Южная ее часть именуется Толбачинским долом. Вдоль осевой части Толбачинского дола в узкой (3-4 км) полосе сосредоточено до $80 \%$ всех эруптивных центров в виде многочисленных трещин и цепочек шлаковых конусов, которые сформировались в течение последних 10 тыс. лет. Извержения за исторический период в этой зоне происходили в 1740 г., в 1941 г. и в 1975-1976 гг. Последнее извержение в 1975-1976 гг. (Большое трещинное Толбачинское извержение - БТТИ) было крупнейшим известным базальтовым извержением в Курило-Камчатском вулканическом поясе. Оно было детально изучено и результаты опубликованы во многих статьях $[1,2,4]$ и обобщающей монографии [5]. БТТИ началось 6 июля 1975 г. и завершилось 10 декабря 1976 г. и состояло из двух этапов: извержения Северного прорыва (6 июля-15 сентября 1975 г.) и извержения Южного прорыва (16 сентября 1975 г. - 10 декабря 1976 г.). Общий объем продуктов извержения составил $2.17 \mathrm{KM}^{3}$, площадь лавовых полей $44.73 \mathrm{KM}^{2}$. Центры современного извержения расположены севернее и ближе к вулкану Плоский Толбачик по сравнению с БТТИ (рис. 1).

По сейсмическим данным образование трещин началось 27 ноября 2012 г., в 17:15 местного времени, фонтанирование лавы и излияние лавовых потоков в 20:00. За 15 часов до начала извержения был зарегистрирован рой слабых землетрясений (максимальная магнитуда 2.25) на глу- 


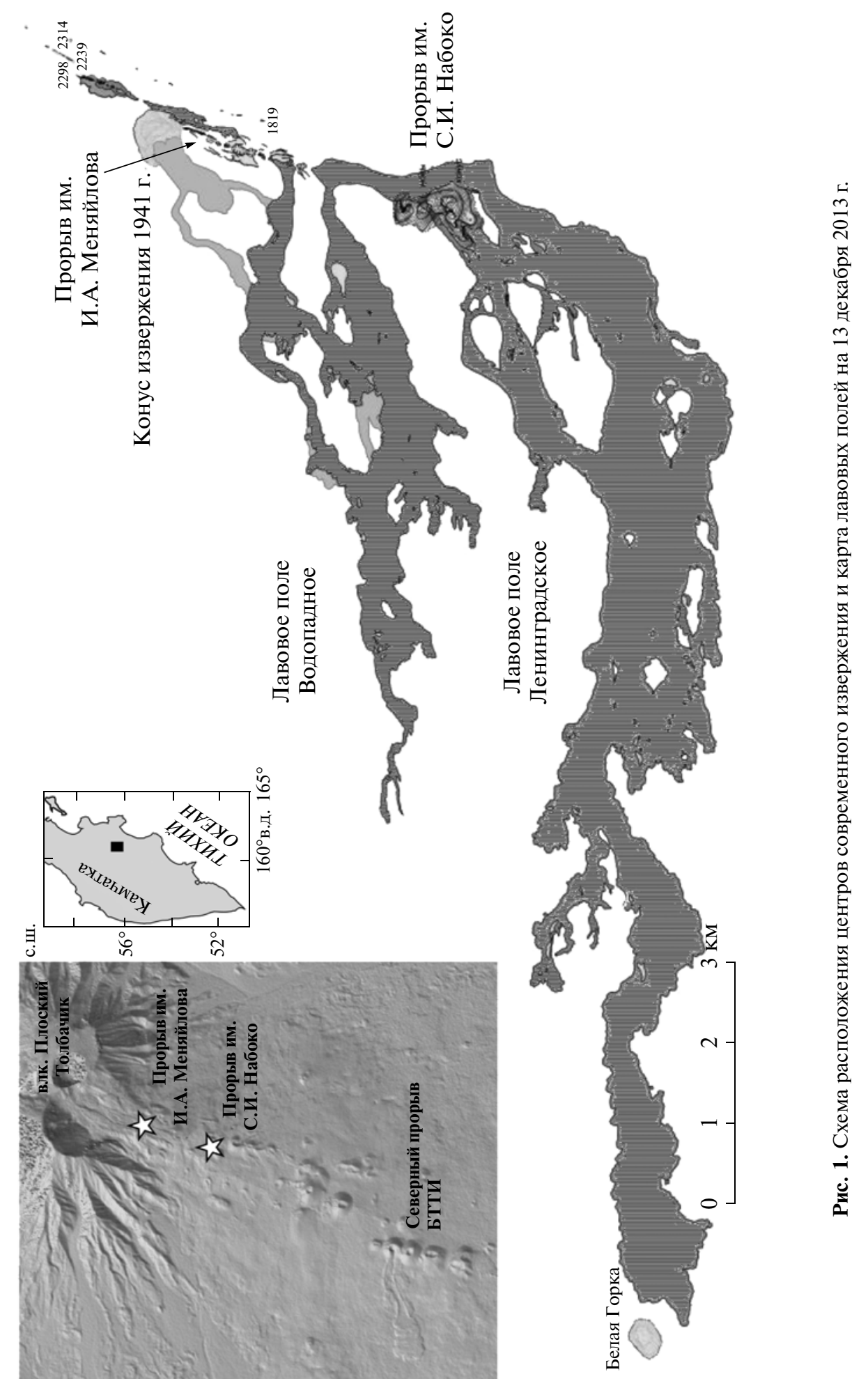


Таблица 1. Параметры лавовых потоков по данным аэрофотосъемки 13 декабря 2012 г.

\begin{tabular}{|c|c|c|}
\hline Параметр & Водопадный & Ленинградский \\
\hline Площадь, км² & 5.654 & 17.035 \\
\hline Объем, км $^{3}$ & 0.027 & 0.208 \\
\hline Средняя мощность, м & 4.8 & 12.2 \\
\hline
\end{tabular}

бинах не более 5 км. В отличие от современного извержения на БТТИ интенсивный рой землетрясений отмечался за 10 сут до его начала, что позволило предсказать время и место извержения [3].

Основными продуктами современного извержения являются лавы. Вначале чрезвычайно интенсивно изливались умеренно вязкие лавовые потоки. В течение первых 43 ч сформировалось два обширных лавовых поля, получивших названия поток “Водопадный” и поток “Ленинградский” (см. рис. 1). Сведения об этих потоках приведены в табл. 1.

В ходе извержения в районе обоих прорывов сформировались небольшие шлаковые конусы, суммарный объем которых на 13 декабря 2012 г. составил $0.008 \mathrm{~m}^{3}$.

Характерной особенностью современного извержения является его эффузивный характер, объемный коэффициент эксплозивности (соотношение объемов пепла и лав) составляет около 3\%. Пепловые выбросы наблюдались в начале извержения, когда работал верхний прорыв. Они сопровождали раскрытие трещины и внедрение лавы в массив мертвых льдов и в многолетнемерзлые породы, покрываюшие южный склон вулкана Плоский Толбачик. Кроме того, непродолжительные пепловые выбросы наблюдались спустя месяц после начала извержения при образовании новых эруптивных центров в пределах нижнего прорыва. Распространение пепла отмечалось на расстояниях до 100 км в север-северо-западном и восточном направлениях от центра извержения. Удельный вес пепловых отложений достигал 500 г $/ \mathrm{M}^{2}$.

Извержение началось с поступления на поверхность высококалиевых глиноземистых трахи-андезибазальтов. Породы начала извержения несколько отличаются от ранее извергнутых пород Толбачинской региональной зоны, в первую очередь, высоким содержанием кремнезема (рис. 2). Кроме того, состав вновь извергнутых пород отличается и от состава пород самого стратовулкана, который в целом имеет более высокое содержание глинозема. Затем, в начале декабря, состав продуктов сменился на более основной. Содер- жание $\mathrm{SiO}_{2}$ упало практически на $2 \%, \mathrm{MgO}, \mathrm{FeO}$ и $\mathrm{TiO}_{2}$ несколько выросло, $\mathrm{Na}_{2} \mathrm{O}$ понизилось, а $\mathrm{K}_{2} \mathrm{O}$ осталось практически постоянным, хотя максимальные его концентрации и вариации составов отмечены именно в породах начала извержения. Породы такого состава извергаются в течение всего последующего периода, вплоть до конца января. Во вкрапленниках к середине декабря появился более крупный плагиоклаз, отдельные таблитчатые кристаллы которого достигают в размерах сантиметра при толщине в 1-2 мм; также появились более крупные по сравнению с началом извержения кристаллы оливина (около 1 мм в поперечнике); общее количество вкрапленников увеличилось.

Для крупных трещинных извержений существует модель, описывающая разгрузку магматического очага $[7,5]$ :

$$
\Omega(t)=\Delta B\left(1-e^{-W_{0} t / \Delta B}\right) .
$$

Здесь $\Omega$ - объем магмы, извергнутой ко времени $t, \Delta B$ - объем магмы, создавшей избыточное давление в очаге перед извержением, $W_{0}$ - начальный расход магмы. Эта модель предполагает экпоненциальную зависимость расхода изверженного материала от времени и позволяет оценить максимальный расход, суммарный объем и длительность извержения по данным о скорости поступления извергаемого вещества на поверхность.

На рис. 3 приводится аппроксимация теоретической зависимости (1) по данным об объемах лавовых полей на 29 ноября 2012 г. и 13 декабря 2012 г., полученным с помощью аэрофотосъемки и результатам обработки спутниковых снимков за 06 марта 2013 г. (данные со спутника EO-1 NASA). Эта аппроксимация дает следующие оценки: максимальный объем извержения $B=0.38 \mathrm{Kм}^{3}$, максимальный расход в начале извержения $W_{0}=$ $=250 \mathrm{~m}^{3} / \mathrm{c}$, длительность извержения 140 дней. Реально наблюдавшийся расход магмы в начале извержения (по данным аэрофотосъемки 29 ноября 2012 г.) превышает $400 \mathrm{~m}^{3} /$ c. Такое существенное различие расчетного и фактического расхода связано с тем, что в начале извержения лава изливалась практически вдоль всей образовавшейся трещины длиной 4-5 км, тогда как формула (1) была получена для канала постоянного сечения. Во время трещинных извержений, как правило, фонтанирование лавы вдоль всей трещины в течение первых нескольких часов локализуется и сменяется извержением из нескольких эруптивных центров [5].

Согласно предварительным результатам анализа спутниковых данных прибора AIRS с использованием известного алгоритма [8] эмиссия диоксида серы $\left(\mathrm{SO}_{2}\right)$ в первые дни извержения 


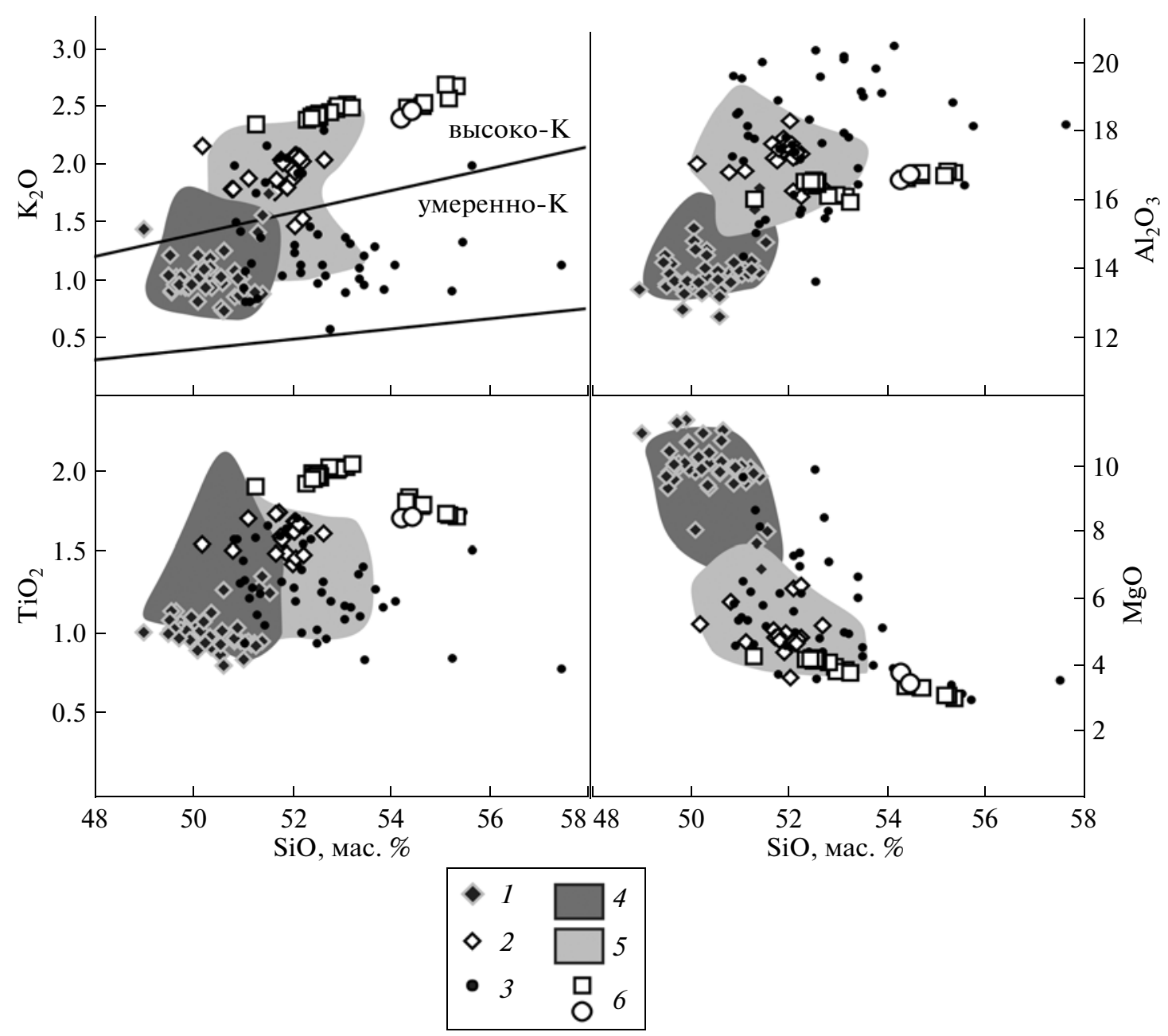

Рис. 2. Вариации содержаний $\mathrm{K}_{2} \mathrm{O}, \mathrm{TiO}_{2}, \mathrm{Al}_{2} \mathrm{O}_{3}$ и $\mathrm{MgO}$ (мас. \%) относительно содержания $\mathrm{SiO}_{2}$ (мас. \%) в породах Трещинного Толбачинского извержения им. 50 -летия ИВиС ДВО РАН, стратовулканов Плоский и Острый Толбачик, БТТИ и региональной зоны. Дискриминационные линии на диаграмме $\mathrm{K}_{2} \mathrm{O}-\mathrm{SiO}_{2}$ по [6]. 1 - северный прорыв БТТИ, 2 - южный прорыв БТТИ, 3 - вулканы Плоский и Острый Толбачик, 4 - магнезиальные базальты ареальной зоны, 5 - глиноземистые базальты ареальной зоны, 6 - Трещинное Толбачинское извержение им. 50-летия ИВиС ДВО РАН: квадраты - лавы и шлаки, круги - пеплы.

(27-28 ноября) составила $5 \cdot 10^{4}$ т. Облако, содержащее газ, под действием метеорологических факторов смещалось в северо-западном направлении (рис. 4). На 28 ноября оно располагалось над южным побережьем Восточно-Сибирского моря и имело площадь до 190 тыс. км². На протяжении следующих нескольких дней оно мигрировало в западном направлении, достигнув Кольского полуострова.

По спутниковым снимкам за 06 марта 2013 г. (данные со спутника EO-1 NASA) площадь лавовых потоков составила $28.7 \mathrm{kм}^{2}$ и объем извергнутого материала около $0.37 \mathrm{~km}^{3}$. Извержение продолжается.

По решению ученого совета Института вулканологии и сейсмологии ДВО РАН извержение получило название "Трещинное Толбачинское

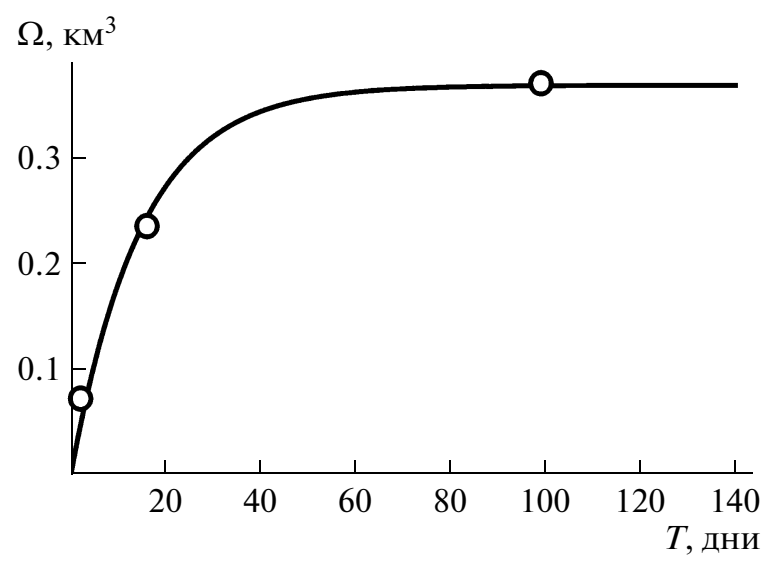

Рис. 3. Рост объема изверженных пород со временем. Точки - данные аэрофотосъемки и обработки спутниковых снимков района извержения. Кривая - аппроксимация по формуле (1). 


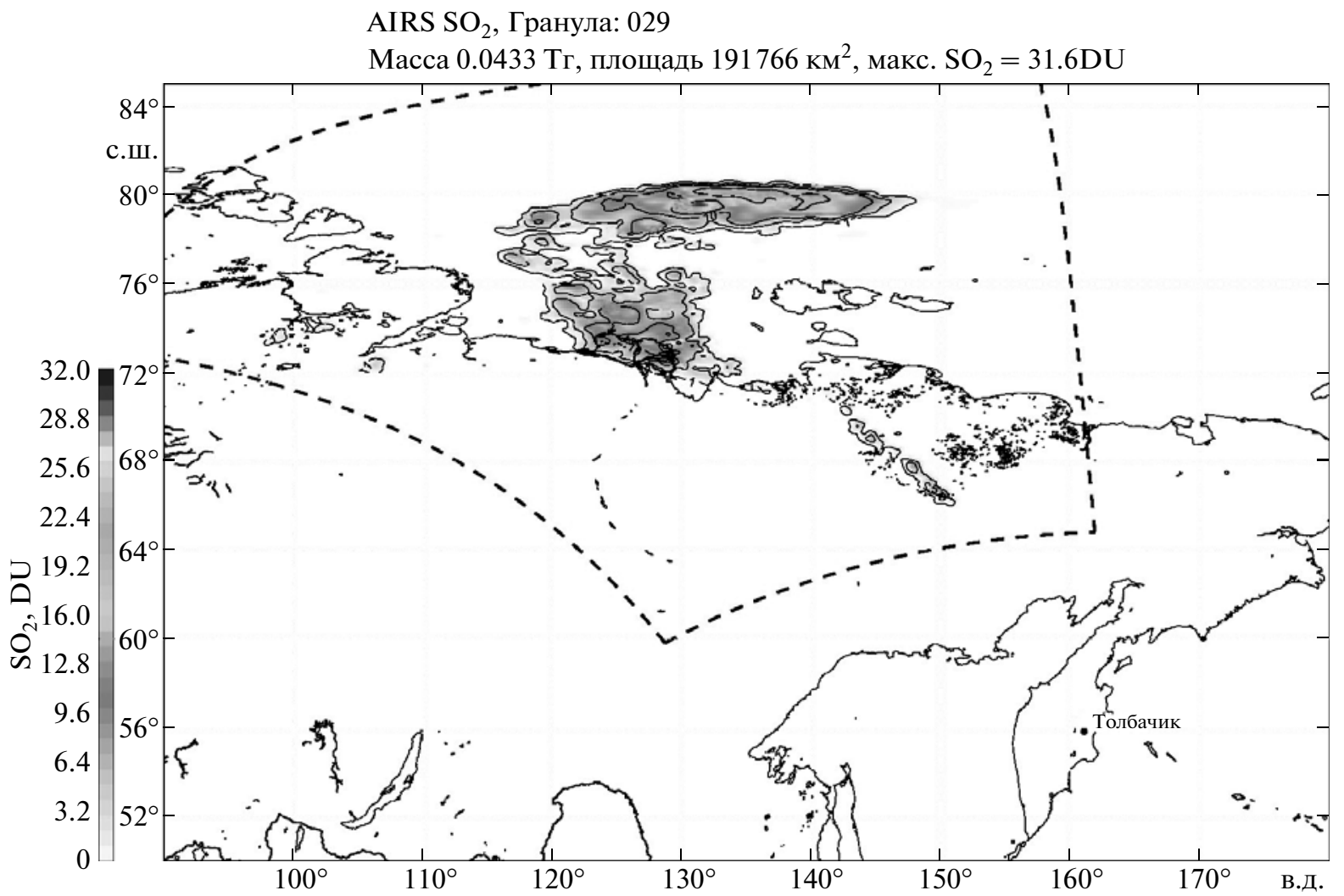

Рис. 4. Положение облака, содержашего диоксид серы, связанного с извержением Толбачика (по спутниковым данным AIRS за 29.11.2013 г., 02:53 UTC). Концентрация приведена в единицах Добсона (DU) (единица Добсона равна 0.01 мм толщины сжатого слоя озона при $0^{\circ} \mathrm{C}$ или $2.69 \cdot 10^{20}$ молекул озона на $\left.1 \mathrm{~m}^{2}\right)$. Штриховая линия - границы спутникового снимка.

извержение имени 50-летия ИВиС (ТТИ-50)”, а верхний и нижний прорывы - "Прорыв им. И.А. Меняйлова" и “Прорыв им. С.И. Набоко” соответственно.

\section{СПИСОК ЛИТЕРАТУРЫ}

1. Волынеи О.Н., Флеров Г.Б., Хренов А.П., Ермаков B.A. // ДАН. 1976. Т. 228. № 6. С. 1419-1422.

2. Федотов С.А., Хренов А.П., Чирков А.М. // ДАН. 1976. T. 228. № 5. C. 1193-1196.

3. Токарев П.И. // ДАН. 1976. Т. 229. № 2. С. 439-442.
4. Федотов С.А., Горельчик В.И., Степанов В.В. // ДАН. 1976. Т. 228. № 6. С. 1407-1410.

5. Большое трещинное Толбачинское извержение, Камчатка 1975-1976 / Под ред. С.А. Федотова. М.: Наука, 1984. 638 c.

6. A Classification of the Igneous Rocks and Glossary of Terms. Recommendations of the International Union of Geological Sciences on the Systematics of Igneous rocks / Le Maitre R.W. Ed. Oxford: Blackwell Sci. Publ., 1989. 193 p.

7. Machado F. In: Physical Volcanology. L.: Elsevier, 1974. $333 \mathrm{p}$.

8. Prata A.J., Bernardo C. // J. Geophys. Res. 2007. V. 112. D20204. 